\title{
IEEE TRANSACTIONS ON MAGNETICS
}

A PUBLICATION OF THE IEEE MAGNETICS SOCIETY

$\begin{array}{llll}\text { MARCH } 2018 \quad \text { VOLUME } 54 & \text { NUMBER } 3 & \text { IEMGAQ } & \text { (ISSN 0018-9464) }\end{array}$

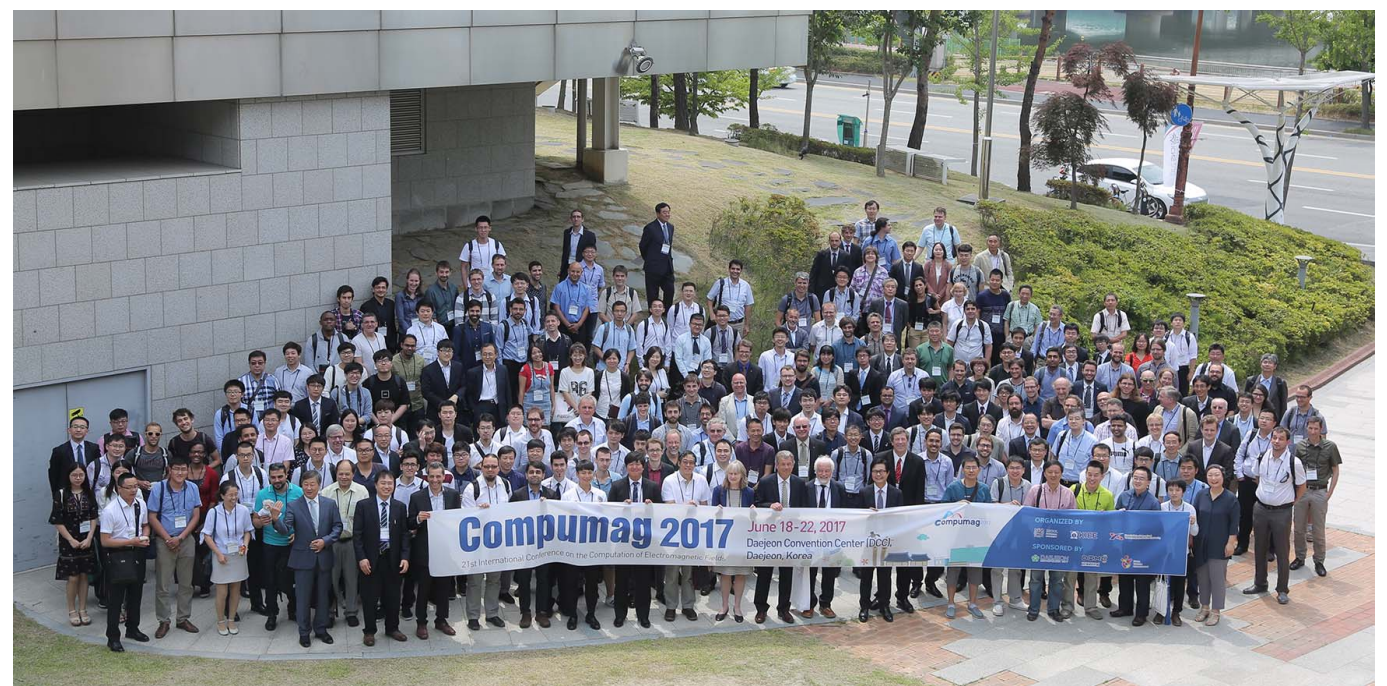

SELECTED PAPERS FROM THE 21st CONFERENCE ON THE COMPUTATION OF ELECTROMAGNETIC FIELDS (COMPUMAG 2017)

Daejeon, South Korea, June 18-22, 2017 


\title{
IEEE MAGNETICS SOCIETY
}

The IEEE Magnetics Society is an association of IEEE members and affiliates with professional interests in the field of magnetics. All IEEE members are eligible for membership in the IEEE Magnetics Society upon payment of the annual Society membership fee of $\$ 26.00$. Membership includes electronic access to IEEE TRANS ACTIONS ON MAGNETICS and IEEE MAGNETICS LETTERS via IEEE Xplore. It is possible for members of other professional societies to become Society affiliates. Information on membership can be obtained by writing to the IEEE at the address below. Member copies of Transactions/Journals are for personal use only.

$$
\begin{array}{cc}
\text { President } & \text { President Elect } \\
\text { Manuel VÁzQuez } & \text { Pallavi DhaGat }
\end{array}
$$

\section{Officers}

\author{
Secretary-Treasurer \\ MASAHIRO YAMAGUCHI
}

Past President BRUCE TERRIS

\section{Director of Operations DiANE MELToN}

\section{Administrative Committee}

Term Ending 31 December 2018

Kaizhong GaO Vincent Mazauric

DAVID Jiles KaTSUJI NAKAGAWA

GanPING Ju Massimo Pasquale

Olga KaZAKova ROBERT LeON Stamps

Honors and Awards, BURKARD HILLEBRANDS Distinguished Lecturers, BETHANIE STADLER Conference Executive Committee, RUDOLF SCHÄFER Education, ATSUFUMI HiROHATA
Term Ending 31 December 2019 Adekunle O. Adeyeye Stephane Mangin DORA ALTBIR MANFRED RUEHRIG Yukiko Kubota RUBen SOMmer ChIH-HuANG LaI Jan SYKULSKI

Standing Committee Chairs

Finance, MINGZHONG Wu Membership, DAN WEI

Nominations, BRUCE TERRIS

Planning, Constitution and Bylaws, Pallavi DHaGAT
Term Ending 31 December 2020

Cindi Dennis June Lau Peter Fischer Hans Nembach

Simon Greaves Teruo ONO MATHIAS KLÄUI THOMAS THOMSON

Publications, PETRU ANDREI

Publicity, PHILIP PONG

Chapters, OKsana ChubyKalo-FESENKo

Technical Committee, LAURA H. LEWIS

\section{Technical Committee}

LAURA H. LEWIS, Chair

Franca ALBERTINi

DARIO ARENA

ELKE ARENHOLZ

JAMES CHANG

ANDRII CHUMAK

CINDI DENNIS

PETER EAMES

PETER FISCHER

DONALD GARDNER

CRISTINA GÓMEZ-POLO

ATSUFUMI HiROHATA

FRANK JOHNSON

SHIKHA JAIN

MYUNG-HWA JUNG

MARK KIEF

MATHIAS KLÄUI

KANNAN KRISHNAN

GALINA KURLYANDSKAYA

MICHAELA KUEPFERLING

NiCOLETA LUPU

\section{Publications Committee}

Petru AndRei, Chair

IEEE Transactions on Magnetics PAVEL KABOS, EDITOR-IN-CHIEF
IEEE Magnetics Letters

Ron B. GOldFARB, CHIEF EdITOR
IEEE Magnetics Society

Newsletter

GARETH P. HATCH, EDITOR

\author{
MARKUS MÜNZENBERG \\ Cajetan (IKENNA) Nlebedim \\ PHILIP PONG \\ JIANG QUAN \\ RAJU RAMANUJAN \\ HosSEIN (NAVID) SEPEHRI AMIN
}

Plamen Stamenov

CARLOS VAZ

JINBO YANG

DAN WEI

YUKIHIRO YOSHIDA

JOHN XIAO

\section{IEEE Officers}

JAMES A. JEFFERIES, President Josè M. F. Moura, President-Elect William P. Walsh, Secretary Joseph V. LiLlie, Treasurer Karen Bartleson, Past President

Ron B. GOLDFARB, Associate Chair

IEEE Press and Publications Liaison JunE LAU
IEEE Journal on Exploratory Solid-State Computational Devices and Circuits RANDALl Victora, STEERING COMMITTEE

Witold M. KinsNer, Vice President, Educational Activities

Samir M. El-Ghazaly, Vice President, Publication Services and Products

Martin J. BastiaAns, Vice President, Member and Geographic Activities

ForRest D. "DON" Wright, President, Standards Association

SuSAN "KATHY" LAND, Vice President, Technical Activities

SANDRA "CANDY" RoBINSON, President, IEEE-USA

JENNIFER T. BERnhARD, Director, Division IV-Electromagnetics and Radiation

IEEE Executive Staff

STEPHEN P. Welby, Executive Director \& Chief Operating Officer

Thomas Siegert, Business Administration

Julie Eve Cozin, Corporate Governance

Donna Hourican, Corporate Strategy

JAmiE MoEsch, Educational Activities

EILEEN M. LACH, General Counsel \& Chief Compliance Officer

VACANT, Human Resources

Chris Brantley, IEEE-USA
CHERIF AMIRAT, Information Technology

KAREN HAWKINS, Marketing

CeCelia Jankowski, Member and Geographic Activities

MiCHAEL FORSTER, Publications

KOnStantinos KaRACHALIOS, Standards Association

MARY WARD-CALLAN, Technical Activities

\author{
IEEE Periodicals \\ Transactions/Journals Department \\ Senior Director, Publishing Operations: DAWN MELlEy \\ Director, Editorial Services: KeVIN LISANKIE Director, Production Services: Peter M. TuOHY \\ Associate Director, Editorial Services: JEFFREY E. CICHOCKI Associate Director, Information Conversion and Editorial Support: VACANT \\ Managing Editor: MARTIN J. MORAHAN Journals Coordinator: MEREDITH FALLON
}

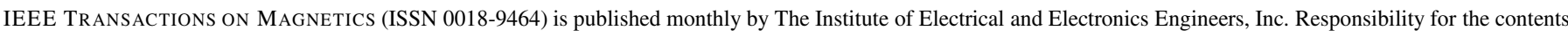

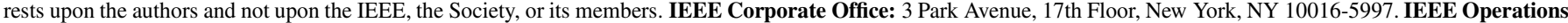

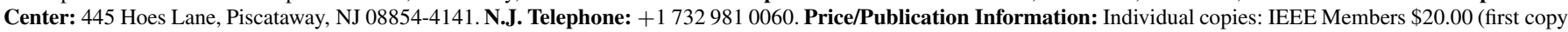

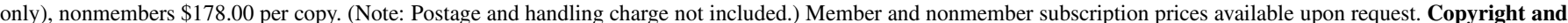

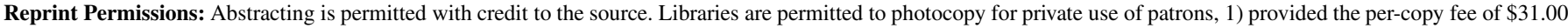

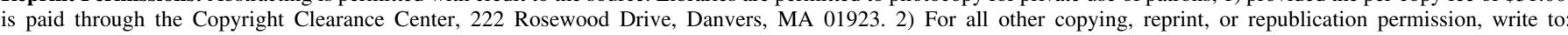

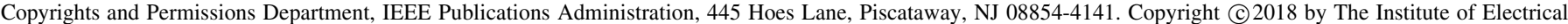

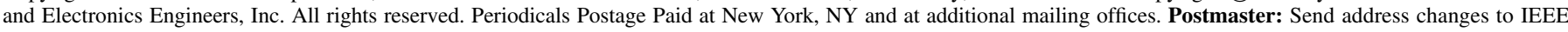

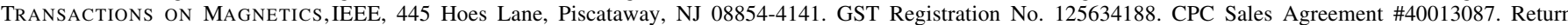

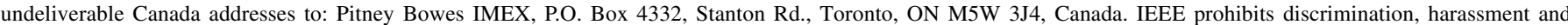
bullying. For more information visit http://www.ieee.org/nondiscrimination. Printed in U.S.A. 


\section{IEEE Transactions on Magnetics \\ Editors}

Pavel Kabos, Editor-in-Chief, National Institute of Standards and Technology, Boulder, Colorado, USA, pavel.kabos@nist.gov

AMR ADLY, University of Cairo, Cairo, Egypt, amradlya @intouch.com

Antonio AZevedo, Universidade Federal de Pernambuco, Brazil, aac@df.ufpe.br

C. Singh Bhatia, National University of Singapore (NUS), Singapore, elebcs@ nus.edu.sg

DANIEl BÜRGLER, Peter Grünberg Institut Electronic Properties, Jülich, Germany, d.buergler@ fz-juelich.de

ZBigniew CeLINSKI, University of Colorado at Colorado Springs, Colorado, USA, zcelinsk@uccs.edu

J. R.CRUZ, The University of Oklahoma, Norman, Oklahoma, USA, jcruz@ ou.edu

Kent DAVEY, The University of Texas at Austin, Austin, Texas, USA, kdavey@ieee.org

DAVID DorRell, University of KwaZulu-Natal Durban, South Africa, dorrelld@ukzn.ac.za LuC DuPRÉ, Universiteit Gent, Ghent, Belgium, luc.dupre@ugent.be

SILVIO DuTZ, Technische Universität Ilmenau, Germany, silvio.dutz@tu-ilmenau.de

JuAn FernandEZ-DE-CASTRO, Seagate Corporation, Bloomington, Minnesota, USA, juan_fdc@ hotmail.com

KEISUKE FUJISAKI, Toyota Technological Institute, Nagoya, Japan, fujisaki@ toyota-ti.ac.jp

KAY HAMEYER, RWTH Aachen University, Aachen, Germany, kay.hameyer@iem.rwth-aachen.de

MANGUi Han, University of Electronic Science and Technology of China, Chengdu, China, mangui@gmail.com

MIN-Fu HSIEH, National Chen Kung University, Taiwan, mfhsieh@mail.ncku.edu.tw

NiCOLETA LuPU, National Institute of R\&D for Technical Physics, Romania, nicole@phys-iasi.ro

LESZEK MALKINSKI, University of New Orleans, New Orleans, Louisiana, USA, lmalkins@uno.edu MANI MinA, Iowa State University, Ames, Iowa, USA, mmina@iastate.edu

S. N. (PRem) PIRAMANAYAGAM, Nanyang Technological University, Singapore, prem@ntu.edu.sg

MARTIN J. SABLIK, Southwest Research Institute, San Antonio, Texas, USA, msablik@ieee.org ANDREI SLAVIN, Oakland University, Michigan, USA, slavin@oakland.edu

NIAN SUN, Northeastern University, Boston, Massachusetts, USA, n.sun@neu.edu

JAN K. SYKULSKI, University of Southampton, Southampton, U.K., jks@ @oton.ac.uk

LALITA UDPA, Michigan State University, East Lansing, Michigan, USA, udpal@egr.msu.edu

JIABIN WANG, The University of Sheffield, Sheffield, U.K., j.b.wang@sheffield.ac.uk

MASAhIRO YAMAGUCHI, Tohoku University, Sendai, Japan, yamaguti@ecei.tohoku.ac.jp

MACIEJ ZBOROWSKI, Cleveland Clinic, Cleveland, Ohio, USA, zborowm@ccf.org

ZHEN ZHANG, Tianjin Unisversity, China, zhangz@eee.hku.hk

Albrecht JANDER, Advances in Magnetics Editor, Oregon State University, Corvallis, Oregon, USA, jander@eecs.orst.edu

LAURA H. LEwIS, Conference Editor, Northeastern University, Boston, Massachusetts, USA, lhlewis@ coe.neu.edu

Prospective authors of extended invited papers should contact the Advances in Magnetics Editor. Conferences interested in publishing selected, peer-reviewed papers in IEEE TRANSACTIONS ON MAGNETICS should contact the Conference Editor.

\section{Editorial Board}
J. A. BAIN
E. Della TORRe
O. KAZAKOVA
Y. K. KIM
R. D. MCMICHAEL
N. D. RIZZO
T. SUZUKI
W. C. CAIN
J. FIDLER
I. D. MAYERGOYZ
A. Patapoutian
A. Prabhakar
S. RUSSEK
T. SCHREFL
B. VASIC
R. H. VICTORA

INFORMATION FOR AUTHORS

The IEEE TRANSACTIONS ON MAGNETICS is published 12 times per year. Submitted manuscripts should be in areas of science and technology related to the basic physics of magnetism, magnetic materials, applied magnetics, and magnetic devices.

The submission of a manuscript to the IEEE TRANSACTIONS ON MAGNETICS implies that it has not been copyrighted or published and that it has not been submitted or accepted for publication elsewhere. All manuscripts considered for publication are subject to peer review and the established technical and editorial standards of the TRANSACTIONS. The IEEE TRANSACTIONS ON MAGNETICS strongly discourages courtesy authorship. It is the obligation of the authors to cite relevant prior work. IEEEs plagiarism guidelines are available at https://www.ieee.org/publications_standards/publications/rights/plagiarism/index.html

The TRANSACTIONS is available electronically on IEEE Xplore, http://ieeexplore.ieee.org/

The IEEE TRANSACTIONS ON MAGNETICS publishes articles in the following five categories:

1) Classics in Magnetics-re-publications of articles that represent important landmarks in the development of magnetics.

2) Advances in Magnetics - technical articles providing critical reviews of current topics by noted experts.

3) Contributed Papers-unsolicited technical articles of archival values, typically less than 15 printed pages in length.

4) Communications-short technical articles of archival value, limited to a maximum of four printed pages in length. Communications are not intended to report preliminary work.

5) Selected Conference Papers - technical articles of archival value in connection with certain magnetics related conferences. Authors submitting papers in this category must follow specific instructions provided by special conference guest editors and send their manuscripts directly to those editors.

Procedure for Submitting a Contributed Article: An IEEE style guide, Information for Authors, and other author tools are available at http://www.ieee.org/ publications_standards/publications/authors/authors_journals.html. For detailed instructions on the preparation of papers, scroll down to "Word Template for Transactions on Magnetics" and download either TRANSMAG.DOC or TRANSMAG.PDF. All manuscripts should be submitted electronically on Manuscript Central, $\mathrm{https://mc.manuscriptcentral.com/transmag-iee.} \mathrm{English} \mathrm{language} \mathrm{editing} \mathrm{services} \mathrm{can} \mathrm{help} \mathrm{refine} \mathrm{the} \mathrm{language} \mathrm{of} \mathrm{your} \mathrm{article} \mathrm{and} \mathrm{reduce} \mathrm{the} \mathrm{risk} \mathrm{of} \mathrm{rejection} \mathrm{without}$ review. IEEE authors are eligible for a 10\% discount at American Journal Experts; visit http://www.aje.com/go/ieee/ to learn more. Please note these services are fee-based and do not guarantee acceptance. Authors encountering problems should contact transmag@ieee.org.

ORCID Required: All IEEE journals require an Open Researcher and Contributor ID (ORCID) for all authors. To create an ORCID, please visit: https://orcid.org/register. The author will need a registered ORCID in order to submit a manuscript or review a proof in this journal.

Author Names in Native Languages: IEEE supports the publication of authors' native-language names in parentheses following their Roman alphabet versions. Native-language names should be submitted in Unicode characters. Chinese authors may use either simplified or traditional characters. For more information, please see http://www.ieee.org/publications_standards/publications/authors/auth_names_native_lang.pdf.

Graphical Abstract: This journal accepts graphical abstracts and they must be peer reviewed. For more information about graphical abstracts and their specifications, please visit the following link: http://www.ieee.org/publications_standards/publications/graphical_abstract.pdf.

Open Access: This publication is a hybrid open-access journal. For a fee of $\$ 1950$, authors have the option of making their articles freely available under open access. Details are available at http://mc.manuscriptcentral.com/transmag-ieee.

Page Charges: IEEE TRAnSACtions on MAgnetics does not solicit page charges. Authors may order reprints; detailed instructions will accompany the galley proof. Color printing is available for a charge of $\$ 275$ per figure. The corresponding author of the article will have the opportunity to address the color-in-print option during an "Article Setup" step. All invoices and payments are handled through an automated payment portal system. The payment portal allows various payment types such as credit card, bank wire transfers, check, pre-approved waivers, special payment circumstances, and third party billing. Please note that split payments are not supported at this time. If you have any questions, please contact oaprocessing@ieee.org for Open Access processing and reprints@ ieee.org for all other charges. There is no charge for color figures in the electronic version.

Copyright: It is the policy of the IEEE to own the copyright to the technical contributions it publishes on behalf of the interests of the IEEE, its authors, and their employers, and to facilitate the appropriate reuse of this material by others. To comply with the U.S. Copyright Law, authors are required to sign an IEEE Copyright Form before publication. This form, a copy of which appears at http://www.ieee.org/documents/ieeecopyrightform.pdf, returns to authors and their employers full rights to reuse their material for their own purposes. Authors will be required to file a copyright form electronically when their paper is submitted for publication.

Digital Object Identifier 10.1109/TMAG.2018.2801641 


\section{Peer-Reviewed Compilation: Manuscripts from Compumag 2017 Chairman's Foreword}

$\mathbf{T}$ HE 21st edition of the International Conference on the Computation of Electromagnetic Fields (Compumag 2017) took place from June 18 to 22, 2017, at the Daejeon Convention Center (DCC), in Daejeon-referred to as "Asia's Silicon Valley"-in South Korea. The conference has been held every two years since the first meeting in Oxford, U.K., in 1976, and has provided a discussion forum for the international community of researchers studying electromagnetic fields. Compumag provides a great opportunity to exchange ideas productively, contributing to the development of innovative technologies and new research areas. We hope computational electromagnetics will continue to prosper, and electromagnetic systems will improve partly thanks to Compumag 2017.

As a premier technical conference on the numerical computation of electromagnetic fields, Compumag 2017 attracted over 400 researchers from 29 countries in five continents. The fact that $33 \%$ of the attendees were students demonstrates the attractiveness of the relevant research fields, including mathematical modeling and formulations, multi-physics and coupled problems, novel computational methods, numerical techniques, optimization and design, etc. The Technical Program Committee of the Conference received 730 papers covering 12 major topics. The digests were thoroughly reviewed, each by at least two reviewers, following Compumag regulations and IEEE TRANSACTIONS ON MAGNETICS standards. In total, 454 papers were selected for presentation, of which 122 were from China, making the largest contribution, followed by South Korea with 90 and Japan with 45. Thanks to the enthusiasm and effort of a number of researchers, leading-edge research on novel techniques and methodologies was presented, especially in optimization and design with 134 papers, static and quasi-static fields with 51, and numerical techniques with 45. In addition, a variety of other topics were covered in oral sessions, with a total of 147 participants sharing their research findings through active debate and discussion. We hope this sharing of ideas at Compumag 2017 will contribute to the technological development of computational electromagnetics.

Compumag 2017 featured 29 poster and 8 oral sessions, attended by 417 delegates from 29 countries. As the conference was hosted by the DCC with large exhibition halls, we were able to create a wonderful atmosphere for enthusiastic discussions. In particular, during the conference, the Rita Trowbridge Award was presented to those young researchers who demonstrated the highest technical quality throughout the conference. The awards committee was chaired by Professor Ruth Sabariego, KU Leuven, Belgium. The first prize was awarded to Sebastian Schuhmacher, Magstadt, Germany, and runner-up commendations to Ji Qiao, Tsinghua University, China; Shingo Hiruma, Hokkaido University, Japan; and Bernard Kapidani, University of Udine, Italy.

All authors of the papers presented at the conference were invited to submit extended and enhanced manuscripts for publication in IEEE TRANSACTIONS ON MAGNETICS. We hope that you will find all work published useful and inspirational for the next Compumag.

Compumag 2017 was organized thanks to the effort of many professors and students from several universities in South Korea. My deep gratitude goes to all volunteers, reviewers, and all those who contributed to the organization. I would particularly wish to thank Prof. Chang-Seop Koh, Prof. Kyung Choi, Prof. Sang-Yong Jung, and Prof. Jang-Young Choi, for their hard work and for making the event such a success. Finally, on behalf of the organizers, I want to thank all the participants and I hope you have wonderful memories of Compumag 2017. We now all look forward to Compumag 2019 in Paris.

Hyun-Kyo Jung, General Chair Compumag 2017 


\title{
IEEE TRANSACTIONS ON MAGNETICS
}

\author{
A PUBLICATION OF THE IEEE MAGNETICS SOCIETY
}

MARCH 2018

VOLUME 54

NUMBER 3

IEMGAQ

(ISSN 0018-9464)

\section{SELECTED PAPERS FROM THE 21st CONFERENCE ON THE COMPUTATION OF ELECTROMAGNETIC FIELDS (COMPUMAG 2017)}

Daejeon, South Korea, June 18-22, 2017

0200201 Compumag 2017 Chairman's Foreword

H.-K. Jung

0200301 Preface From the Editor-in-Chief

J. Sykulski

0200402 Compumag 2017 Conference Organization

\section{PAPERS}

Theory and Computation: Spin Phenomena, Dynamics, Interactions

1300105 Core Loss Calculation Based on Finite-Element Method With Jiles-Atherton Dynamic Hysteresis Model Y. Li, L. Zhu, and J. Zhu

1300204 Electromagnetic Field Analysis Considering Reaction Field Caused by Eddy Currents and Hysteresis Phenomenon in Laminated Cores

K. Yamazaki and Y. Sakamoto

1300304 Effects of Multi-Axial Mechanical Stress on Loss Characteristics of Electrical Steel Sheets and Interior Permanent Magnet Machines

K. Yamazaki, H. Mukaiyama, and L. Daniel

1300404 Shape Optimization Procedure of Interior Permanent Magnet Motors Considering Carrier Harmonic Losses Caused by Inverters

K. Yamazaki and Y. Togashi

Soft Magnetic Materials, Alloys and Films

2000304 Numerical Modeling and Material Characterization for Multilayer Magnetically Shielded Room Design

A. Canova, F. Freschi, L. Giaccone, and M. Repetto

Hard Magnetic Materials, Alloys and Films

2100404 Pulsed-Field Magnetometer Measurements and Pragmatic Hysteresis Modeling of Rare-Earth Permanent Magnets

G. Glehn, S. Steentjes, and K. Hameyer

2100505 A Hysteresis Model Based on Linear Curves for NdFeB Permanent Magnet Considering Temperature Effects

J. Chen, D. Wang, S. Cheng, Y. Jiang, X. Teng, Z. Chen, Y. Shen, F. Birnkammer, and D. Gerling

Nanostructured and Patterned Materials

2300304 Study of Strain Effects on Carbon-Based Transistors With Semi-Analytic and Ab Initio Models Y. Zheng, F. Zanella, G. Valerio, C. A. Dartora, and Z. Ren 
7203404 A Full-Wave Integral Equation Method Including Accurate Wide-Frequency-Band Wire Models for WPT Coils

S. Bilicz, Z. Badics, S. Gyimóthy, and J. Pávó

7203504 Electromagnetic Simulation of Rotating Propeller Blades for Radar Detection Purposes

K. Marák, T. Petô, S. Bilicz, S. Gyimóthy, and J. Pávó

7203604 Coupling Volume and Surface Integral Formulations for Eddy-Current Problems on General Meshes

P. Bettini, M. Passarotto, and R. Specogna

7203704 Adaptive Sampling of Physical Optics Currents Based on EFIE Error Prediction

J.-H. Kim, Y.-S. Chung, G. C. Park, and H.-K. Jung

7203804 Iterative Kriging-Based Methods for Expensive Black-Box Models

S. Deng, R. El Bechari, S. Brisset, and S. Clénet

7203904 Transient Behavior of Large Transformer Windings Taking Capacitances and Eddy Currents Into Account

K. Preis, W. Renhart, A. Rabel, and O. Bíró

7204004 Enhanced Meta-Model-Based Optimization Under Constraints Using Parallel Computations R. El Bechari, S. Brisset, S. Clénet, and J.-C. Mipo

7204104 Adjoint Technique for Sensitivity Analysis of Coupling Factors According to Geometric Variations S. Schuhmacher, A. Klaedtke, C. Keller, W. Ackermann, and H. De Gersem

7204204 High-Frequency Electromagnetic Field Analysis by COCR Method Using Anatomical Human Body Models

A. Takei, M. Ogino, and S. Sugimoto

7204304 Data-Driven Multi-Element Arbitrary Polynomial Chaos for Uncertainty Quantification in Sensors

O. Alkhateeb and N. Ida

7204404 Stability Analysis of Time Domain Discontinuous Galerkin H- $\Phi$ Method for Eddy

Current Simulations

J. Smajic, M. Bucher, R. Christen, and Z. Tanasic

7204504 Multi-Domain Transmission Conditions for Domain Decomposition Methods Applied to Scattering Problems

I. A. Baratta and E. J. Silva

7204604 Efficient Perturbation Method for Computing Two-Port Parameter Changes Due to Foreign Objects for WPT Systems

J. Pávó, Z. Badics, S. Bilicz, and S. Gyimóthy

7204704 An Adaptive FEM Based on Magnetic Field Conservation Applying to Ferromagnetic Problems S. Noguchi, S. Matsutomo, and V. Cingoski

7204804 SCSM for Calculation of Motion-Induced Eddy Currents in Isotropic and Anisotropic Conductive Objects

M. Ziolkowski, R. Schmidt, B. Petković, S. Gorges, J.-M. Otterbach, K. Weise, and H. Brauer

7204904 Finite-Element Analysis for Surface Discharge Due to Interfacial Polarization at the Oil-Nanocomposite Interface

J.-H. Choi, S.-H. Kim, K. Jang, M. Hikita, and S.-H. Lee

7205004 Eddy-Current-Effect Homogenization of Windings in Harmonic-Balance Finite-Element Models Coupled to Nonlinear Circuits

R. V. Sabariego, K. Niyomsatian, and J. Gyselinck

7205104 New Type of Second-Order Tetrahedral Edge Elements by Reducing Edge Variables for Quasi-Static Field Analysis

A. Ahagon, A. Kameari, H. Ebrahimi, K. Fujiwara, and Y. Takahashi

7205204 H-Formulation Using the Discontinuous Galerkin Method for the 3-D Modeling of Superconductors

L. Makong, A. Kameni, L. Queval, F. Bouillault, and P. Masson 


\title{
An Adaptive FEM Based on Magnetic Field Conservation Applying to Ferromagnetic Problems
}

\author{
So Noguchi ${ }^{\circledR 1,2}$, Shinya Matsutomo ${ }^{\circledR 3}$, and Vlatoko Cingoski ${ }^{4}$ \\ ${ }^{1}$ Graduate School of Information Science and Technology, Hokkaido University, Sapporo 060-0814, Japan \\ ${ }^{2}$ National High Magnetic Field Laboratory, Florida State University, Tallahassee, FL 32310 USA \\ ${ }^{3}$ National Institute of Technology, Niihama College, Niihama 792-8580, Japan \\ ${ }^{4}$ Faculty of Electrical Engineering, University “Goce Delcev"-Stip, 1000 Skopje, Macedonia
}

\begin{abstract}
We have previously been proposed a novel adaptive finite-element method (FEM) based on a magnetic field conservation indicator and a non-conforming mesh-refinement technique. However, we have applied to a very simple model consisting of a single permanent magnet for basic verification of the proposed method. In this paper, we have improved an error indicator, and tried to apply a newly proposed adaptive FEM to more complicated models, where ferromagnetic material is included. The newly proposed method is superior in torque error estimation to the Zienkiewicz-Zhu error estimation method in a 3-D permanent magnet motor model.
\end{abstract}

Index Terms-Adaptive finite-element method (FEM), error estimation, magnetic field conservation, non-conforming mesh.

\section{INTRODUCTION}

A NOVEL adaptive finite-element method (FEM) has previously been proposed utilizing a magnetic field conservation evaluation as an error indicator and a non-conforming mesh-refinement technique as a mesh-refinement scheme [1]. Our goal is to improve the simulation accuracy with less number of elements. Though the performances of PCs are enhanced, the generation of an unnecessary large number of elements is undesirable to adaptive FEMs.

Some error indicators were proposed [2]-[5], and an error indicator based on the conservation of magnetic field $H$ on the interface between two elements [1], [5] are very promising from the mathematical viewpoint. Meanwhile, a few kinds of non-conforming techniques were also proposed such as the discontinuous Galerkin method [6], the mortar FEM [7], and the mesh interpolating method [8]. The interpolating method is well suited for the proposed adaptive FEM [1].

The previously proposed adaptive FEM resulted in the generation of a suitably dense mesh with less number of elements. The proposed method has two advantages: 1) it is possible to indicate an error on element surfaces between different materials and 2) it is easy to subdivide badly evaluated elements into smaller ones, even though they are elements on object boundary. That is, it is easily applicable to a complicated simulation model including iron cores or plural kinds of materials. However, we have never shown any result of models containing multiple materials.

In this paper, first of all, two modifications on the error indicator are shown. Then, the proposed adaptive FEM is applied to two models: a single permanent magnet and iron core model, and a surface permanent magnet (SPM) motor model. In the SPM motor model, the computation of torque is enhanced using the proposed error indication. It is well known that it is difficult to compute the torque without

Manuscript received June 27, 2017; revised August 25, 2017; accepted September 12, 2017. Corresponding author: S. Noguchi (e-mail: noguchi@ ssi.ist.hokudai.ac.jp).

Color versions of one or more of the figures in this paper are available online at http://ieeexplore.ieee.org.

Digital Object Identifier 10.1109/TMAG.2017.2754862

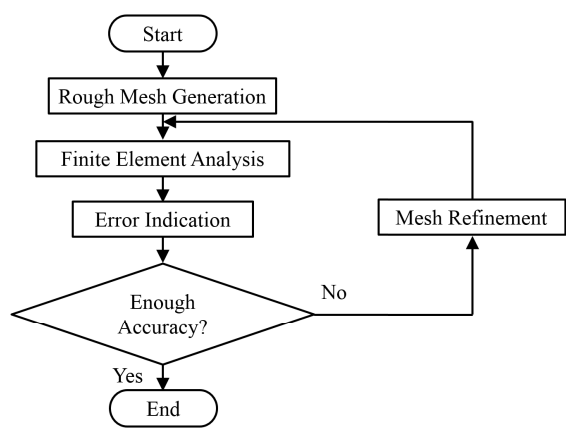

Fig. 1. Flow of the traditional adaptive FEM.

using a symmetrical mesh. However, the proposed method derives an accurate torque even though non-symmetric mesh is initially used. The obtained results are compared with the Zinkiewicz-Zhu (ZZ) error estimation method results.

\section{Adaptive Edge-Based Finite-Element Method}

Fig. 1 shows the flow of a common adaptive FEM. The magnetic field conservation indicator [5] and the non-conforming mesh-refinement technique are used in the proposed method [1]. In this paper, an edge-based tetrahedral finite element is employed.

\section{A. Error Indicator Based on Magnetic Field Conservation}

As an error indicator, a weighted tangential component of magnetic field $d$ was proposed in the previous paper [1] as follows:

$$
d_{i, j}=\int_{S}\left(\boldsymbol{H}_{i} \times \boldsymbol{w}_{j}\right) \cdot \boldsymbol{n}_{i} d S \quad(i=1,2 \text { and } j=a, b, c)
$$

where $i, j, S, \boldsymbol{H}, \boldsymbol{w}$, and $\boldsymbol{n}$ are the indices of adjacent elements and edges (see Fig. 2), the element surface, the magnetic field strength, the vector interpolation function, and the unit vector normal to the element surface $S$, respectively. However, on the surface of permanent magnet, the indicator (1) must be

$$
d_{i, j}=\int_{S}\left(\left(\boldsymbol{H}_{i}-\boldsymbol{K}_{i}\right) \times \boldsymbol{w}_{j}\right) \cdot \boldsymbol{n}_{i} d S
$$




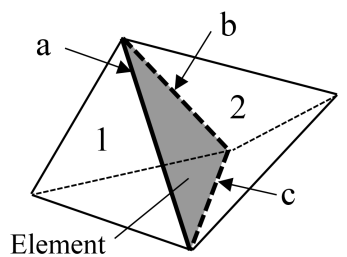

Interface $S$

Fig. 2. Adjacent tetrahedral elements 1 and 2 with common edges a, b, and $\mathrm{c}$.

where $\boldsymbol{K}$ is the equivalent surface current on the surface of permanent magnet.

Due to the magnetic field conservation, the following equations with respect to all three edges per element surface must hold:

$$
D_{j}=d_{1, j}+d_{2, j}=0 \quad(j=a, b, c) .
$$

As a result of the conventional edge-based FEM, the values of $D_{j}$ are not zero. Therefore, as the final error indicator $E$ of the previous paper [1], we proposed

$$
E=\max \left(\left|D_{a}\right|,\left|D_{b}\right|,\left|D_{c}\right|\right) .
$$

However, the value of the error indicator $E$ strongly depends on the angle between the vector $(\boldsymbol{H}-\boldsymbol{K})$ and the edges. Therefore, we have newly proposed the following error indicator:

$$
\bar{E}=\left(\left|D_{a}\right|^{2}+\left|D_{b}\right|^{2}+\left|D_{c}\right|^{2}\right)^{\frac{1}{2}} .
$$

Using (5), the new error indicator $\bar{E}$ is independent of the angle between the vector $(\boldsymbol{H}-\boldsymbol{K})$ and the edges. Since the component of magnetic field $\boldsymbol{H}$ tangential to the element surface is continuous on the boundary of different materials, this error indicator becomes useful, robust, and effective.

\section{B. Non-Conforming Mesh Refinement Scheme}

A mesh-refinement task is burdensome in the conventional adaptive FEM. As a mesh-making method, the Delaunay triangulation method is well known and widely used. However, many ill-quality elements, such as flat or inside-out elements, are often generated with adaptive steps. In the proposed meshrefinement scheme, one element indicated with a large error is subdivided into eight smaller elements. Actually, using the above error indicator, two elements are simultaneously evaluated, so two elements with a large error become 16 smaller elements. Some of these elements to be subdivided have a surface sharing with an element not to be subdivided, a nonconforming surface is generated there (see Fig. 3). Since nodes are placed on edges for element subdivision, the nonconforming refinement scheme is easily applicable to elements even on the boundary of analysis objects. The level difference of subdivision between two neighboring tetrahedrons is limited to two, in order to avoid the sudden change of mesh density. The large mesh-size difference would make it difficult to solve the system equations.

As shown in [1], the proposed method reuses all the created constitutional matrices $\boldsymbol{C}$ on every adaptive step. As the result, on the $i$ th step, we can obtain the following system:

$$
C_{1}^{t} \ldots C_{i}^{t} L_{i} C_{i} \ldots C_{i} \tilde{\mathbf{a}}_{i}=C_{1}^{t} \ldots C_{i}^{t} \boldsymbol{b}_{i}
$$

where $\boldsymbol{L}, \tilde{\boldsymbol{a}}$, and $\boldsymbol{b}$ are the stiffness matrix, the vector potential on master edges, and the source vector, respectively.

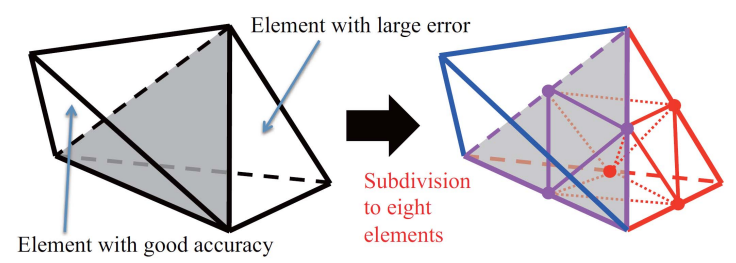

Fig. 3. Subdivision from an element with large indicated error to eight smaller elements, as the result, some smaller element has a non-conforming surface connecting to a not-subdivided element.

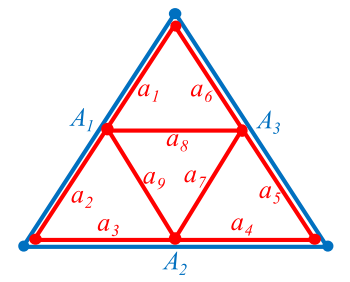

Fig. 4. Geometrical relation of master (red lines) and slave (blue lines) edges. In this relation, $a_{1-9}$ are the unknown variables, however, $A_{1}, A_{2}$, and $A_{3}$ are interpolated from $a_{1}$ and $a_{2}, a_{3}$ and $a_{4}$, and $a_{5}$ and $a_{6}$, respectively.

In our non-conforming scheme, the larger surface is employed as a slave, and the smaller as a master. On the geometrical relation shown in Fig. 4, the relation between the master and slave is obtained as follows:

$$
C \tilde{a}=\left[\begin{array}{lllllllll}
1 & 1 & 0 & 0 & 0 & 0 & 0 & 0 & 0 \\
0 & 0 & 1 & 1 & 0 & 0 & 0 & 0 & 0 \\
0 & 0 & 0 & 0 & 1 & 1 & 0 & 0 & 0 \\
1 & 0 & 0 & 0 & 0 & 0 & 0 & 0 & 0 \\
0 & 1 & 0 & 0 & 0 & 0 & 0 & 0 & 0 \\
0 & 0 & 1 & 0 & 0 & 0 & 0 & 0 & 0 \\
0 & 0 & 0 & 1 & 0 & 0 & 0 & 0 & 0 \\
0 & 0 & 0 & 0 & 1 & 0 & 0 & 0 & 0 \\
0 & 0 & 0 & 0 & 0 & 1 & 0 & 0 & 0 \\
0 & 0 & 0 & 0 & 0 & 0 & 1 & 0 & 0 \\
0 & 0 & 0 & 0 & 0 & 0 & 0 & 1 & 0 \\
0 & 0 & 0 & 0 & 0 & 0 & 0 & 0 & 1
\end{array}\right]\left[\begin{array}{l}
a_{1} \\
a_{2} \\
a_{3} \\
a_{4} \\
a_{5} \\
a_{6} \\
a_{7} \\
a_{8} \\
a_{9}
\end{array}\right]=\left[\begin{array}{l}
A_{1} \\
A_{2} \\
A_{3} \\
a_{1} \\
a_{2} \\
a_{3} \\
a_{4} \\
a_{5} \\
a_{6} \\
a_{7} \\
a_{8} \\
a_{9}
\end{array}\right] .
$$

Using the constitutional matrix (7), the vector potentials on subdivided edges are unknown, meanwhile those on the parent edges before subdivision are obtained from the interpolation of subdivided edges.

On each adaptive step, the system of equations is not renumbered and not compressed in our program code. The matrix diagonals on the slave edges are 1, meanwhile the other elements are 0. Although the memory wastes, it is easy to make a program of adaptive FEM as a hierarchical repeatable function. The obtained system is solved by the conventional incomplete Cholesky conjugate gradient.

\section{APPLICATIONS}

To confirm the validity of the proposed adaptive FEM, it was applied to two models including ferromagnetic materials: a simple model and an SPM motor model.

\section{A. Simple Model (Permanent Magnet and Iron Core)}

The proposed adaptive method is robust to models consisting of multiple materials with different permeability, such as a permanent magnet and an iron. To show the effectiveness of the proposed adaptive FEM, it is applied to a model consisting 


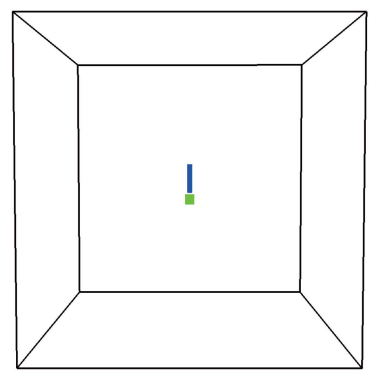

Analysis Condition

$>$ Analysis region:

$\checkmark 714 \mathrm{~mm} \times 714 \mathrm{~mm} \times 714 \mathrm{~mm}$

$>$ Parmanent magnet (green):

$\checkmark 24 \mathrm{~mm} \times 24 \mathrm{~mm} \times 24 \mathrm{~mm}$ $\checkmark 1 \mathrm{~T}$

$>$ Iron (blue)

$\checkmark$ Cylindrical (radius: $12 \mathrm{~mm}$ )

$\checkmark$ Length: $72 \mathrm{~mm}$

$>$ Distance between PM and iron:

$\checkmark 6 \mathrm{~mm}$

Fig. 5. Simple model consisting of a permanent magnet and a long iron bar. The specifications are also shown.

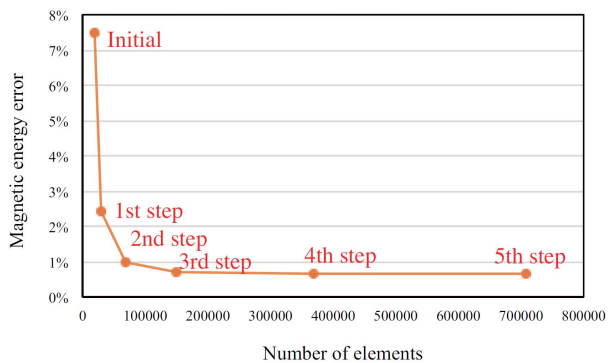

Fig. 6. Magnetic field energy error transition and number of elements with adaptive steps.

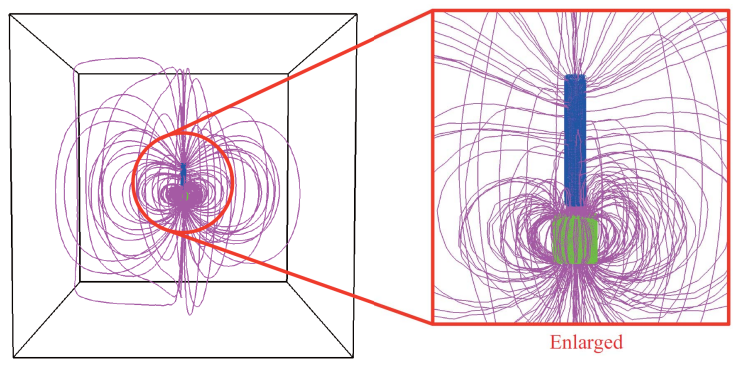

Fig. 7. Visualized flux lines of the simulation results obtained at the fifth step by the proposed adaptive FEM.
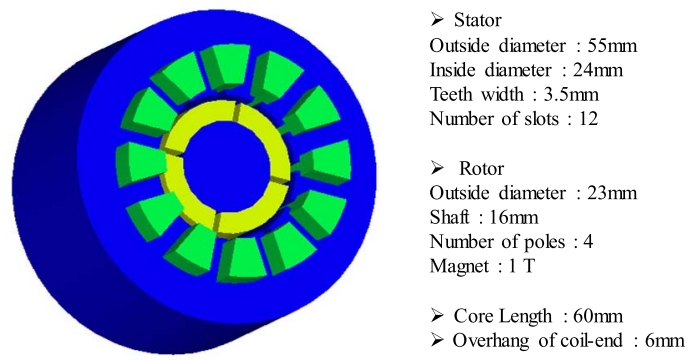

Fig. 8. SPM motor model and simulation specifications.

of a permanent magnet and an iron, as shown in Fig. 5. Fig. 5 also shows the simulation specifications.

The initial rough mesh of 18838 elements was created by commercial software. The magnetic energy error of the initial mesh was $7.48 \%$ as a true value of simulation result with a large number of elements. Fig. 6 presents the magnetic energy error as a function of number of elements. In the first few steps, the magnetic field error is drastically reduced. At the fifth adaptive step, the error decreased to $0.06 \%$ with 708989 elements.

Fig. 7 shows the flux line maps visualized from the simulation result at the fifth adaptive step. The proposed adaptive

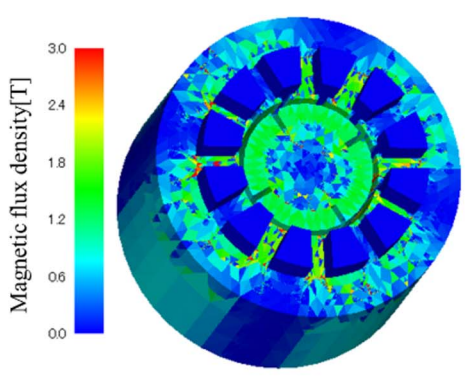

Z-Z method

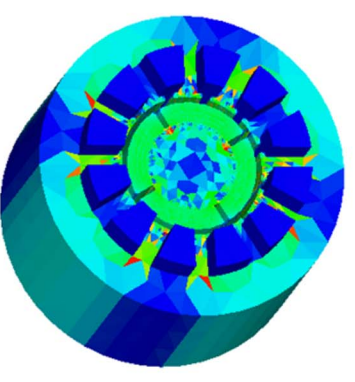

Proposed method
Fig. 9. Finally obtained meshes with magnetic field by Z-Z method (left) and proposed method (right).

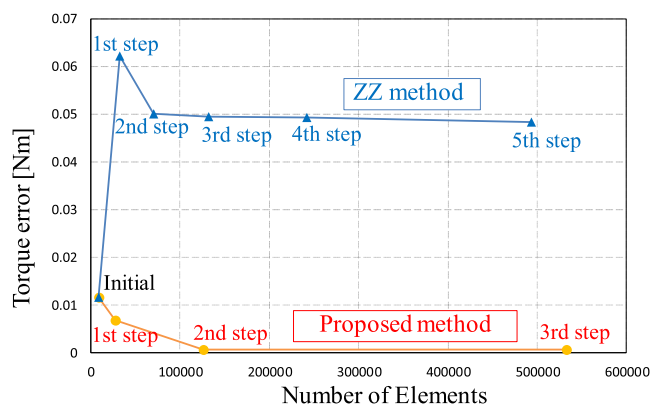

Fig. 10. Torque error as a function of number of elements.

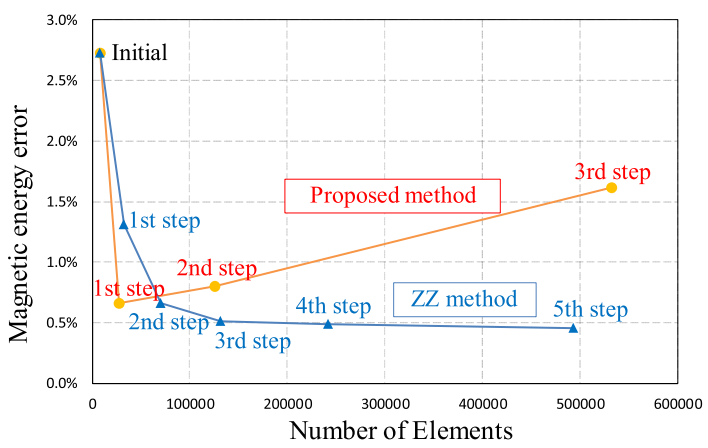

Fig. 11. Magnetic field energy as a function of number of elements.

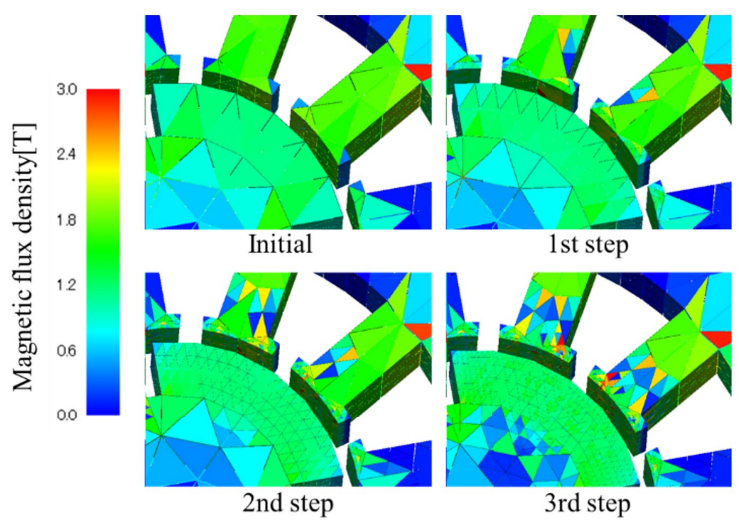

Fig. 12. Enlargement view around air gap as the adaptive step proceeds in the proposed adaptive FEM. Air-gap elements are well subdivided, but the stator and rotor elements are not much subdivided.

FEM works as a smoother of flux lines by improving the discontinuity of the tangential component of magnetic field. Every flux line in Fig. 6 looks like enough smooth. 


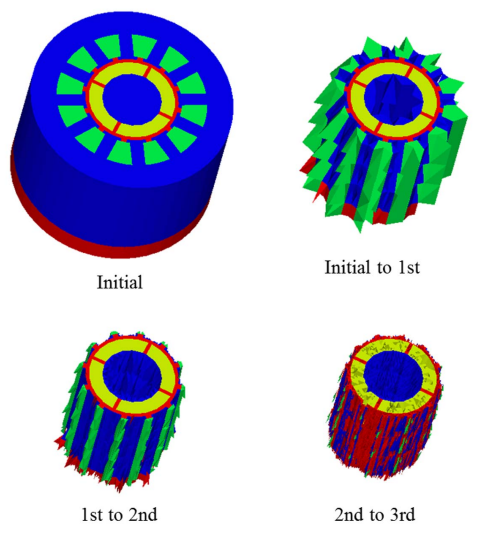

Fig. 13. Element subdivision element map as the adaptive step proceeds in the proposed adaptive FEM.
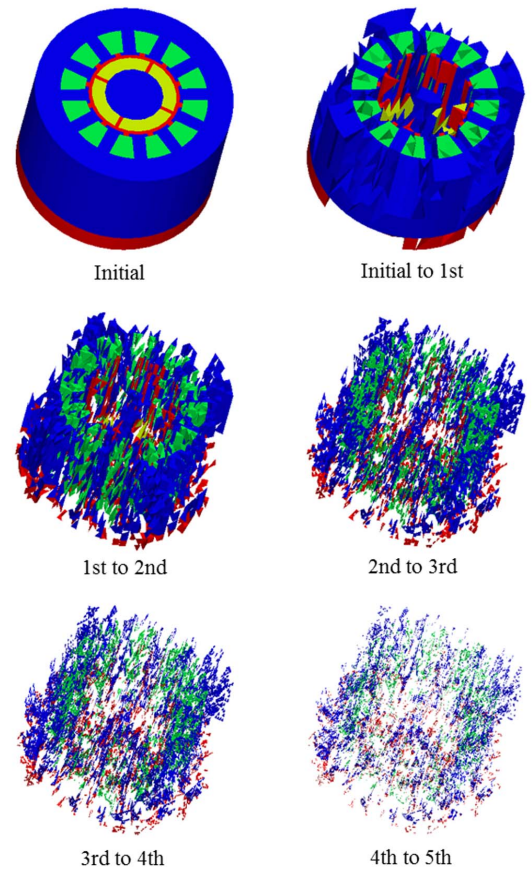

Fig. 14. Element subdivision element map as the adaptive step proceeds in the adaptive FEM with the ZZ method.

\section{B. SPM Motor Model}

Next, the proposed adaptive FEM is applied to an SPM motor model [9]. Fig. 8 shows the motor model, whose initial rough mesh is created with commercial software. The mesh is the coarsest capable to representing the motor structure.

To confirm the validity, the simulation result is compared with that of the $\mathrm{ZZ}$ method. It took approximately $5 \mathrm{~min}$ for three steps in the proposed method and 29 min for five steps in the ZZ method. Fig. 9 plots the magnetic field on the final mesh (the third step in the proposed method and the fifth step in the $\mathrm{ZZ}$ method). The proposed method obviously obtained the smooth magnetic field map.

Figs. 10 and 11 show the torque and magnetic field energy error transitions during the process of adaptation. Here, the true torque is theoretically 0 , and the expected true field energy is obtained from a mesh with a large number of elements $(3.86 \mathrm{~J})$. From the viewpoint of torque, the torque of the proposed method is drastically enhanced due to the improvement of the discontinuity of the tangential magnetic field component. The elements around the air gap are well subdivided as shown in Fig. 12. The final values are $0.7 \mathrm{mNm}$ in the proposed method and $48.4 \mathrm{mNm}$ in the $\mathrm{ZZ}$ method. Meanwhile, the magnetic energy error of the proposed method does not converge to zero. The $\mathrm{ZZ}$ method is superior in the magnetic field energy evaluation, because it evaluates magnetic field energy continuity between adjacent elements as an error indicator.

Next, Fig. 13 indicates the element subdivision map in the proposed adaptive FEM. On every step from the initial to third subdivision mesh, the elements around permanent magnet and air gap are badly evaluated. Fig. 14 shows the element subdivision map with the adaptive step in the $\mathrm{ZZ}$ method. As the adaptive step proceeds, the elements in the entire region are ill evaluated. Since the small elements are distributed in the entire region, the accuracy of the magnetic field energy is enhanced but the torque accuracy is not improved.

\section{CONCLUSiON}

The proposed method was applied to two models containing ferromagnetic materials to show the validity. Since the continuity of the magnetic field tangential to element surface was evaluated in the proposed adaptive FEM, the accuracy of torque computation in the motor model was enhanced. However, the magnetic field energy was badly evaluated.

In near future, the proposed method must be modified to enhance the magnetic field energy error. One reason of the large energy error is that the magnetic field $\boldsymbol{H}$ is too high in the air gap, and the elements in the air gap are over evaluated in the proposed adaptive FEM.

\section{REFERENCES}

[1] S. Noguchi et al., "A new adaptive mesh refinement method in FEA based on magnetic field conservation at elements interfaces and nonconforming mesh refinement technique," IEEE Trans. Magn., vol. 53, no. 6, Jun. 2017, Art. no. 7201904.

[2] O. C. Zienkiewicz and J. Z. Zhu, "The superconvergent patch recovery and a posteriori error estimates. Part 1: The recovery technique," Int. J. Numer. Methods Eng., vol. 33, no. 7, pp. 1331-1364, 1992.

[3] Z. Tang, Y. Le Menach, E. Creuse, S. Nicaise, F. Piriou, and N. Nemitz, "Residual and equilibrated error estimators for magnetostatic problems solved by finite element method," IEEE Trans. Magn., vol. 49, no. 12, pp. 5715-5723, Dec. 2013.

[4] R. Beck, R. Hiptmair, R. H. Hoppe, and B. Wholmuth, "Residual based a posteriori error estimators for eddy current computation," ESAIM: Math. Model. Numer. Anal., vol. 34, no. 1, pp. 159-182, 2000.

[5] S. Nicaise and E. Creuse, "A posteriori error estimation for the heterogeneous Maxwell equations on isotropic and anisotropic meshes," Calcolo, vol. 40, no. 4, pp. 249-271, 2003.

[6] S. Ausserhofer, O. Biro, and K. Preis, "Discontinuous Galerkin finite elements in time domain eddy-current problems," IEEE Trans. Magn., vol. 45, no. 3, pp. 1300-1303, Mar. 2009.

[7] T. Matsuo, Y. Ohtuski, and M. Shimasaki, "Efficient linear solvers for mortar finite-element method," IEEE Trans. Magn., vol. 43, no. 4, pp. 1469-1473, Apr. 2007.

[8] S. Bohmer, C. Kruttgen, B. Riener, and K. Hameyer, "Eddy currents and non-conforming sliding interfaces for motion in 3-D finite element analysis of electrical machines," IEEE Trans. Magn., vol. 51, no. 3, Mar. 2015, Art. no. 8103104.

[9] S. Matsutomo, S. Noguchi, H. Yamashita, and S. Tanimoto, "A new concept for optimal design method considering modeling accuracy of electromagnetic device," IEEE Trans. Magn., vol. 40, no. 2, pp. 1232-1235, Mar. 2004. 


\section{Conference Author Index}

\section{A}

Ackermann, W. 7204104, 7401304

Afonso, M. M. 7400904

Ahagon, A. 7200804, 7205104

Ahn, D.-G. 8201804

Ahn, J.-H. 8200604

Ahn, S. 9400204

Al Achkar, G. 9400304

Alípio, R. 7200304

Alkhateeb, O. 7204304

Alotto, P. 7201204

Amanatiadis, S. A. 7201504

An, S. 7001104

Arkkio, A. 8102004

Ataka, T. 7202804

Auchmann, B. 7000404

Aydin, U. 8102004

\section{B}

Badics, Z. 7203404, 7204604

Bai, B. 8400304

Bai, Y. 7000304

Baratta, I. A. 7204504

Bastos, J. P. A. 7300104

Batistela, N. J. 4000504

Bauernfeind, T. 7001504, 8000504

Baumgartner, P. 7001504, 8000504

Belahcen, A. 7300804, 8102004

Benjelloun, N. 9400304

Benoit, J. 8700304

Bensaid, S. 6200404

Berthiau, G. 6200604

Bettini, P. 7201204, 7202304, 7202404, 7203604

Bilicz, S. 7203404, 7203504, 7204604

Birnkammer, F. 2100505

Bíró, O. 7001504, 7203904, 7400804, 8000504

Boesing, M. 8101604

Bortot, L. 7000404

Bouillault, F. 4600104, 7202904, 7205204

Bracikowski, N. 6000204

Brauer, H. 6200105, 6200504, 7204804

Bretas, A. S. 7200204

Brisset, S. 7203804, 7204004

Bucher, M. 7204404

Bui, H. K. 6200604

Byun, J.-K. 5000104

\section{C}

Canova, A. 2000304

Cao, W. 8200405

Cappanera, L. 4600104

Carpentier, A. 7001604

Chadebec, O. 7000604, 7001604

Chang, J. 8000204, 8101404, 8101904

Chang, K. 8101304

Changgeng, Z. 8400104

Chao, L. 7203304

Chen, B. 7401504
Chen, D. 8400304

Chen, J. 2100505, 7001304, 8102705

Chen, Z. 2100505

Cheng, S. 2100505

Cheon, W. J. 9401004

Chiariello, A. G. 7001804

Cho, H. 7000804

Cho, S.-G. 8200804

Cho, Y.-S. 9400504

Choi, C. T. M. 5100404

Choi, C. Y. 9400804

Choi, J. 9400704

Choi, J.-H. 7204904

Choi, J.-Y. 8200604

Choi, K. K. 7000804, 7000904

Choi, M.-S. 5000104

Christen, R. 7204404

Christopoulos, C. 7200204

Chromik, R. 8101104

Chung, H. J. 7300604

Chung, T.-K. 8201704

Chung, Y.-S. 7203704, 9400504

Cicuttin, M. 7203004

Cingoski, V. 7204704

Clemens, M. 7200604

Clénet, S. 7200904, 7201404, 7202004, 7202604, 7203804, 7204004

Codecasa, L. 7203004

Cortes Garcia, I. 7000404

Cosoroaba, E. 5100804

Coulomb, J.-L. 7001604

Cozza, A. 8700304

Creusé, E. 7401204

Cui, K. 5000204

\section{D}

Daikoku, A. 7200804

Daniel, L. 1300304, 9400304

Dartora, C. A. 2300304

de Araujo Elias, R. 4000504

Debray, Q. 7001604

De Gersem, H. 7204104, 7401304

Degui, Y. 7203304

De Lorenzi, A. 7202404

Demenko, A. 8102304

Deng, S. 7203804

Deri, Y. 7202104

Di Barba, P. 7001704, 9400604

Ding, W. 8102804

Di Rienzo, L. 6300104

Dłotko, P. 7400404

Dolezel, I. 7401404, 8000304

Dölker, E.-M. 6200105

Dong, J. 8000704

Dong, S. 6200305

Dozono, H. 7401504

Du, X. 7200404, 8102905

Duan, J. H. 7001704

Duan, N. 8000804

Ducharne, B. 6100204, 6200204

Ducreux, J.-P. 7401204
$\mathbf{E}$

Ebrahimi, H. 7200704, 7201804, 7205104

El Bechari, R. 7203804, 7204004

F

Fahimi, B. 5100804

Fan, D. 8102104

Fan, Y. 4600204

Fang, S. 8000404,8101805

Farah, A. A. M. 7400904

Feng, H. 8400204

Fernandez Navarro, A. M. 7000404

Formisano, A. 7001804

Fouladgar, J. 6200604

Freschi, F. 2000304

Fu, D. 6000204

Fu, W. N. 7201005

Fujiki, T. 7401504

Fujita, S. 7401005, 7401104

Fujiwara, K. 7200804, 7205104

Furuya, A. 7202804

G

Galopin, N. 7000604

Gao, B. 7203304

Gao, Y. 7401504

Gazzana, D. S. 7200204

Ge, M. 5000204

Geng, Y. 8000704

Gerling, D. 2100505

Ghorbanian, V. 8101104

Giaccone, L. 2000304

Gillon, F. 6000204

Glehn, G. 2100404

Gong, J. 6000204

Gorges, S. 7204804

Goursaud, B. 7202604

Gragger, J. V. 7300304

Guan, W. 7401504

Guermond, J.-L. 4600104

Guichon, J.-M. 7000604

Günther, M. 8102504

Guo, Y. 8102204, 8102404

Guo, Z. 8400204

Gupta, B. 6100204, 6200204

Gyimóthy, S. 7203404, 7203504, 7204604

Gyselinck, J. 7202704, 7205004

\section{H}

Hackl, A. 7001504, 8000504

Hahn, S. 7201904

Hamar, R. 7401404, 8000304

Hameyer, K. 2100404

Hamidizadeh, S. 8101104

Han, K. J. 9400704 


\section{IEEE Transactions on Magnetics}

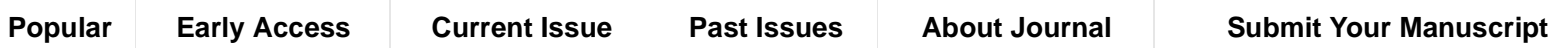

\section{About this Journal \\ Aims \& Scope \\ Author Resources \\ IEEE Author Digital Toolbox Additional Information IEEE Open Access Publishing Options}

\section{Sponsor}

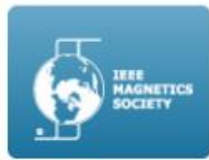

\section{Contacts}

Editor-in-Chief

Pavel Kabos

National Institute of Standards and Technology

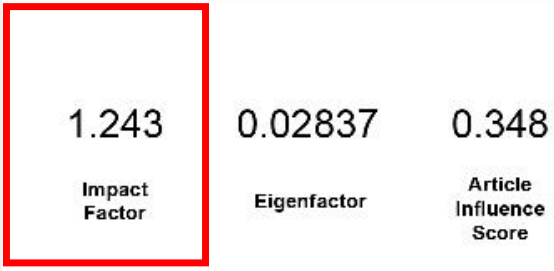

\section{Aims \& Scope}

Science and technology related to the basic physics and engineering of magnetism, magnetic materials, applied magnetics, magnetic devices, and magnetic data storage. The IEEE Transactions on Magnetics publishes scholarly articles of archival value as well as tutorial expositions and critical reviews of classical subjects and topics of current interest.

Persistent Link: http://ieeexplore.ieee.org/servlet/opac?punumber=20

Frequency: 12

ISSN: 0018-9464

Publication Details: IEEE Transactions on Magnetics

\section{Subjects}

Fields, Waves \& Electromagnetics
Published by:

\section{- IEEE Magnetics Society}

\section{Contacts}

Editor-in-Chief

Pavel Kabos

National Institute of Standards and

Technology

Boulder, CO 80305 USA

pavel.kabos@nist.gov

Phone: 303-497-3997

Editorial Office

Franklin Jones

transmag@ieee.org 